\title{
Treatment with iron increases weight gain and psychomotor development
}

\author{
M A AUKETT, Y A PARKS, P H SCOTT, AND B A WHARTON \\ Sorrento Maternity Hospital, Birmingham
}

SUMmaRY Previous work at this hospital and elsewhere has shown that anaemia in toddlers is common and is associated with psychomotor delay. It seemed unclear, however, whether this association was cause and effect or merely due to the same underprivileged environment. A double blind randomised intervention study was, therefore, performed. After an initial assessment 97 children with anaemia (haemoglobin 8-11 g/dl) aged 17-19 months received either iron and vitamin $\mathrm{C}$ or vitamin $\mathrm{C}$ only (control group) for two months and were then reassessed. The children who received the iron had an increased rate of weight gain and more of them achieved the expected rate of development. While iron deficiency anaemia is unlikely to be the only factor in the slower development of children living in underprivileged circumstances, it can at least be easily identified and treated. Routine child health surveillance in such areas should include a haemoglobin determination.

The impact of protein energy malnutrition on intellectual development in developing countries has been extensively investigated. ${ }^{1}$ In the developed world protein energy malnutrition is uncommon but iron deficiency is widespread. ${ }^{2}$

The relation between anaemia and cognitive development has been studied. Work in animals suggested that iron deficiency anaemia may adversely affect cognitive development and behaviour, ${ }^{3}$ and studies in adults, ${ }^{4}$ older children, and young adolescents $^{5}$ also showed an effect on behaviour and performance. Recent interest has been in preschool children. In 1973 a study of 230 children aged 4-5 years in New Orleans found that anaemia was associated with lower scores on testing of intelligence quotients. ${ }^{6}$ Another study of 68 babies aged 6-24 months in Guatemala showed infants with anaemia to have substantial developmental deficits compared with their normal peers. ${ }^{7}$ Similarly, in a group of children born in this hospital and seen again in their 'toddler' years (around 20 months) iron deficiency anaemia was very common and again was apparently associated with slower development. ${ }^{8}$ It is not clear, however, whether the iron deficiency causes the delay or merely the two are associated evidence of an underprivileged environment.

Previous work on the use of iron supplements has yielded conflicting evidence. Some studies have shown an improvement in development using oral treatment with iron, ${ }^{9}$ others have not. ${ }^{7}$ Intramuscular treatment with iron may work, ${ }^{10}$ but the suitability of giving iron in this way to toddlers can be questioned. Evaluation of these studies is difficult because of the wide age range of children included, ${ }^{710}$ small sample numbers, ${ }^{79-11}$ differing control groups, ${ }^{9-11}$ and differences in the definition of iron deficiency. Also as they all used short term treatment (seven to 15 days) the differences shown may have just related to short term behaviour changes.

This study was, therefore, designed to determine the effect of psychomotor development of giving oral treatment with iron for two months to toddlers with anaemia living in an inner city underprivileged environment.

\section{Patients and methods}

Recruitment of patients. The parents of every child aged 17-19 months living in the catchment area of four child health clinics in central Birmingham were sent an invitation to attend for routine surveillance, including a haemoglobin estimation; 470 children attended. The normal clinic procedures-that is, assessment of growth and development and physical examination-were carried out as usual by the community child health service staff. In addition, capillary blood for estimation of haemoglobin was 
taken by one of two project nurses. Distribution of haemoglobin concentration in children attending the child health clinics is shown in Figure 1. The World Health Organisation has proposed that a haemoglobin concentration of less than $11 \mathrm{~g} / \mathrm{dl}$ may be used to identify anaemia in children between the ages of 6 months and 6 years. ${ }^{12}$ Thus $26 \%$ of the children screened were 'anaemic' using this criterion. Eight (2\%) of the Asian children were severely anaemic (haemoglobin $<8 \mathrm{~g} / \mathrm{dl}$ ). They were investigated and treated immediately. They all had simple iron deficiency anaemia. A further $25 \%$ of the Asian children and $18 \%$ of the others (almost all European) had a haemoglobin concentration between 8 and $11 \mathrm{~g} / \mathrm{dl}$, and these were recruited to the study.

Investigation and treatment plan. (Fig. 2) The children with a haemoglobin concentration of 8-11 $\mathrm{g} / \mathrm{dl}$ were invited to an anaemia clinic at our hospital. Informed and written consent to the study was obtained and the patient's general practitioner informed. The following procedures were carried out.

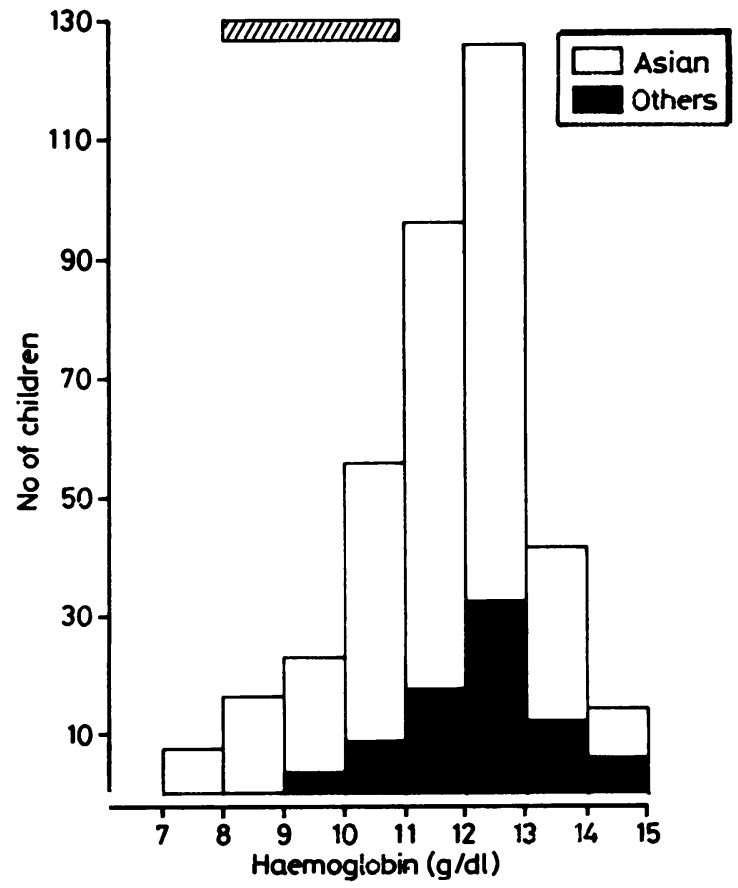

Fig.1 Distribution of haemoglobin concentration in 470 children aged 17-19 months attending four child health clinics in inner Birmingham. Children within the hatched area were subsequently enrolled in the intervention study.
Social, family, and medical history

This was taken by the project nurses and interpreter as necessary and checked by one of us (AA or YP) using a standard form-for example, ethnic group, mother's education, housing, etc.

\section{Growth}

Growth measurements were made by the project nurses. Weight was taken with the child naked on a lever balance; length using a Harpenden Stadiometer; and head circumference by paper tape.

\section{Haematological}

One millilitre of capillary blood was taken for measurement of haemoglobin and red blood cell indices, haemoglobin electrophoresis, plasma iron concentration, which was measured colorimetrically using the Guanidine/Ferrozine method (J T Baker, Deventer, Holland), ${ }^{13}$ transferrin, measured on a Baker Encore centrifugal analyser using antihuman transferrin (Hoecht UK Ltd, Hounslow, Middlesex) and calibrated with human transferrin (Boehringer Mannheim, West Germany), and ferritin estimation (Enzyme immunoassay, Hybritch Europe SA, Liege, Belgium).

Psychomotor development

The children were tested by one of us (AA or YP) with 24 items taken from the Denver developmental screening test ${ }^{14}$ appropriate for the age group studied. The items were presented in the standardised manner required by the test using the standard proforma and materials. ${ }^{15}$ The number of items that the child achieved was counted, up to a maximum possible of 24

The age at which $25,50,75$, and $90 \%$ of children will pass has been determined for each item. ${ }^{14}$ Children who are average in every respect-that is, on the 50th percentile-would achieve 13 items at 18 months and 19 items at 20 months - that is, in the normal course of development they would achieve six more of the psychomotor skills tested during the two months of the study. A similar difference is seen between 19 months and 21 months-that is, six extra skills. The Denver developmental screening test was chosen as the basis for psychomotor assessment because of its suitability for the age group tested, ease of administration by a non-psychologist, good test-retest reliability, and reliability among examiners. It has been validated against the Bayley scales of infant development and the Stanford-Binet and has been standardised for use in multiracial communities. ${ }^{141617}$ As $90 \%$ of the children with anaemia were Asian and for many the first language of both mother and child was not English an interpreter attached to the project was used as an 
aid to the examiners in all developmental assessments.

\section{Treatment}

The children with anaemia then received either iron $24 \mathrm{mg}$ (as ferrous sulphate) plus vitamin C 10 $\mathrm{mg}$ daily or vitamin $\mathrm{C} 10 \mathrm{mg}$ alone daily. Allocation was double blind using consecutively numbered bottles (the code was only known to the hospital pharmacist). Both supplements were in the form of a palatable mixture, which looked identical. One month's supply was given at the anaemia clinic. The project nurses visited every child at two weekly intervals to encourage compliance and to take a further supply of the supplement at the end of one month.

After two months (eight to nine weeks) the children reattended and were reassessed as above. No result of any investigation from the first anaemia clinic was available until after the two month assessment was completed. A number of children in both groups had to be 'chased' to reattend for the second appointment; 15 of the treated and 17 of the placebo group were seen after the two month period (mean 75 and 76 days, respectively). As far as we are aware the only variable in the way the children were handled was whether the supplement given contained iron or not, and this variation was double blind.

Patients studied. (Table 1) The social and anthropometric details of the two groups of children who completed the intervention trial were similar, although despite randomisation the mean age of the treated group was 0.5 months below the untreated group (mean (SD): $17.9(0.7)$ months $v$ 18.4 (0.8) months, $\mathrm{p}<0.01)$. On average the children were slightly lighter and shorter than the United States reference standard. ${ }^{18}$

Analysis of results. The measurement of outcomethat is, improvement in haematology and weight velocity and extra skills achieved-were for the purpose of analysis firstly regarded as continuous variables, which were compared in the groups using the $t$ test for significance. Then the number of children achieving various indices of normality were examined-for example, haemoglobin $\pm 11 \mathrm{~g} / \mathrm{dl}$, weight gain $\pm 7 \mathrm{~g} / \mathrm{dl}$, and extra skills learned \pm 6 - using the $\chi^{2}$ test with Yates's correction for significance. For each of these measurements of outcome the results were analysed as a 'pragmatic' clinical trial ${ }^{19}$ - that is, one designed to determine whether an iron supplement offered to toddlers with anaemia enhanced the acquisition of psychomotor skills. For this purpose the children who completed
Table 1 Characteristics of the 98 children entered in the study (Mean (SD))

\begin{tabular}{|c|c|c|}
\hline \multirow[t]{2}{*}{ Feature } & \multicolumn{2}{|l|}{ Group } \\
\hline & $\begin{array}{l}\text { Iron plus } \\
\text { vitamin } C\end{array}$ & $\begin{array}{l}\text { Vitamin } C \\
\text { only }\end{array}$ \\
\hline \multicolumn{3}{|l|}{ Social factors } \\
\hline No & 48 & 49 \\
\hline Sex (M:F) & $27: 21$ & $29: 20$ \\
\hline \multicolumn{3}{|l|}{ Ethnic group: } \\
\hline Asian & 42 & 43 \\
\hline European & 2 & 4 \\
\hline African & 2 & 2 \\
\hline Other & 1 & 0 \\
\hline Maternal age & $27 \cdot 3(5 \cdot 9)$ & $27 \cdot 2(4 \cdot 9)$ \\
\hline No of sibs & $2 \cdot 4(2 \cdot 1)$ & $2.4(1.5)$ \\
\hline \multicolumn{3}{|l|}{ Years in United Kingdom: } \\
\hline All & $9.4(7 \cdot 8)$ & $10.5(7 \cdot 6)$ \\
\hline Asians only & $7 \cdot 5(5 \cdot 3)$ & $8.5(5.4)$ \\
\hline \multicolumn{3}{|l|}{ Grade of educational class:* } \\
\hline 0 & $0: 25$ & 0:19 \\
\hline 1 & $1: 7$ & $1: 3$ \\
\hline 2 & $2: 13$ & $2: 15$ \\
\hline 3 & $3: 2$ & $3: 5$ \\
\hline 4 & $4: 1$ & $4: 3$ \\
\hline 5 & 5:0 & $5: 4$ \\
\hline Occupants per room $\dagger$ & $1.3(0.5)$ & $1.3(0.4)$ \\
\hline Important birth history $\ddagger$ & 3 & 2 \\
\hline Important previous medical history $\$$ & 7 & 6 \\
\hline Age at first test (months) & $17.9(0 \cdot 7)$ & $18.4(0 \cdot 8)$ \\
\hline \multicolumn{3}{|l|}{ Anthropometry at first visit } \\
\hline Height & $81 \cdot 2(2 \cdot 6)$ & $82.0(3 \cdot 2)$ \\
\hline Weight & $11.0(1.4)$ & $10.9(1.3)$ \\
\hline Head circumference $(\mathrm{cm})$ & $47.4(1.4)$ & $47.2(1.8)$ \\
\hline \multicolumn{3}{|l|}{ Standard deviation score:\| } \\
\hline Weight & $-0.14(1.24)$ & $-0.28(0.98)$ \\
\hline Height & $-0.14(0.87)$ & $+0.02(0.87)$ \\
\hline Weight for height & $-0.02(1.41)$ & $-0.27(1.10)$ \\
\hline
\end{tabular}

*Grades: $0=$ no education; $1=1-5$ years primary education; 2=6-11 years, including secondary education; $3=$ sixth form; $4=$ vocational training; $5=$ college. $\dagger>1.5=$ Overcrowded.

‡For example, caesarean section for breech in special care baby unit for two days, preterm.

\$For example, dextrocardia and chest infection, giardiasis, detached retina, diarrhoea, and vomiting.

||Using NICHS standards. ${ }^{18}$

the assessment protocol were divided into two treatment groups-those offered iron and those offered placebo-and the results compared. The results were also analysed as an 'explanatory' clinical trial ${ }^{19}$ to test the hypothesis, 'Does a significant rise in haemoglobin (as indicated by a rise of at least $2 \mathrm{~g} / \mathrm{dl}$ ) enhance the acquisition of psychomotor skills in children with anaemia?' For this purpose, the children who completed the protocol were divided into two haemoglobin groups-those in whom the haemoglobin concentration rose by at least $2 \mathrm{~g} / \mathrm{dl}$ and those in whom it did not-and the results compared.

\section{Results}

Effect of treatment on haematological measurements. (Table 2) As was expected the haemoglobin 
Table 2 Haematological values before and after treatment (Mean (SD))

\begin{tabular}{|c|c|c|c|c|}
\hline & \multicolumn{4}{|l|}{ Group } \\
\hline & \multicolumn{2}{|c|}{ Iron plus vitamin $C(n=48)$} & \multicolumn{2}{|c|}{ Vitamin $C$ only $(n=49)$} \\
\hline Haemoglobin (g/dl) & $9.9(0.9)$ & $12 \cdot 1(1 \cdot 0)$ & $10 \cdot 1(0 \cdot 8)$ & $10.4(1.3)$ \\
\hline No $<11$ & 48 & 6 & 49 & 33 \\
\hline Mean corpuscular volume (fl) & $61.9(7 \cdot 1)$ & $67 \cdot 6(6 \cdot 2)$ & $61 \cdot 0(6 \cdot 7)$ & $61 \cdot 5(7 \cdot 0)$ \\
\hline Mean corpuscular haemoglobin (pg) & $19 \cdot 8(2 \cdot 8)$ & $22 \cdot 4(2 \cdot 6)$ & $19 \cdot 6(2 \cdot 6)$ & $19 \cdot 7(3 \cdot 0)$ \\
\hline No $<24$ & 44 & 32 & 46 & 46 \\
\hline Serum iron $(\mu \mathrm{mol} / \mathrm{l})$ & $8 \cdot 3(4 \cdot 3)$ & $13 \cdot 0(7 \cdot 1)$ & $8.7(3.9)$ & $8.7(3.6)$ \\
\hline No $<9$ & $30 / 43$ & $11 / 43$ & $24 / 47$ & $32 / 47$ \\
\hline Transferrin saturation $(\%)$ & $6.9(4 \cdot 8)$ & $13.5(9 \cdot 8)$ & $7.6(5.9)$ & $6.9(5.0)$ \\
\hline No $<15$ & $40 / 43$ & $29 / 43$ & $42 / 47$ & $42 / 47$ \\
\hline Ferritin (ng/nl) & $8 \cdot 7(4-3)$ & $12 \cdot 9(7 \cdot 2)$ & $7 \cdot 7(3 \cdot 9)$ & $7 \cdot 7(4.4)$ \\
\hline No $<7$ & $18 / 43$ & $7 / 42$ & $24 / 47$ & $21 / 47$ \\
\hline
\end{tabular}

Cut off points are the usual accepted lower limits of normal for this age group. ${ }^{12} 20-22$

concentration rose in the group receiving iron and the indices of iron deficiency all improved.

Effect of treatment on weight velocity. (Fig. 3) The rate of weight gain in the children who received iron was greater than in those who did not $(\mathrm{p}<0.001$ by $t$ test). Regarding individual results, whereas $75 \%$ of the treated group increased their weight by $7 \mathrm{~g}$ per day or more (the derived 50th centile), only $48 \%$ of the untreated group did so $\left(\mathrm{p}<0.001\right.$ by $\chi^{2}$ test).

The rate of weight gain in the children whose haemoglobin concentration rose by at least $2 \mathrm{~g} / \mathrm{dl}$ was greater than in those whose haemoglobin did not ( $\approx 0.05$ by $t$ test). Of those whose haemoglobin concentration rose by at least $2 \mathrm{~g} / \mathrm{dl}, 72 \%$ increased their weight by $7 \mathrm{~g}$ or more, but so did $56 \%$ of those whose haemoglobin concentration did not rise more than $2 \mathrm{~g} / \mathrm{dl}$ (not significant).

Effect of treatment on psychomotor development. (Fig. 4) Group results were analysed first. The mean increase in psychomotor skills in the children

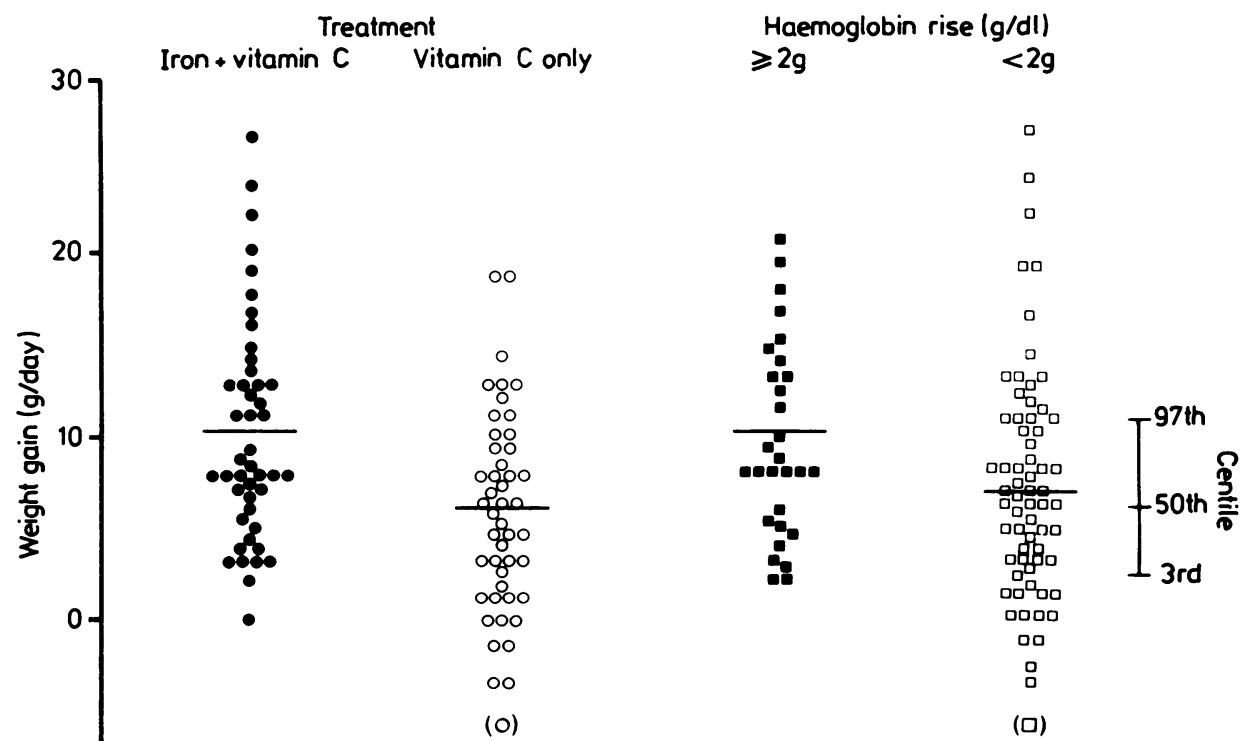

$-10 」$

Fig. 3 Weight velocity according to treatment group and change in haemoglobin concentration. Centile numbers are based on whole year weight velocity standards for boys aged 1-5 years. ${ }^{23}$ 


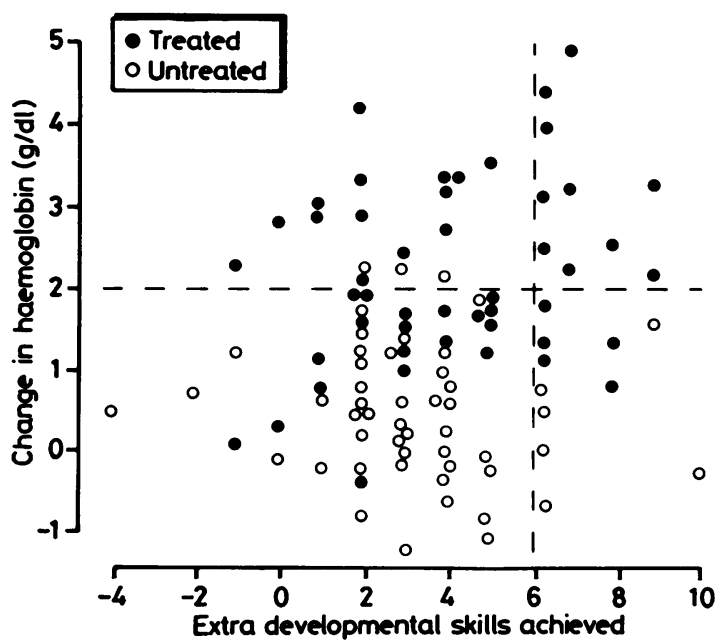

Fig. 4 Effect of treatment on psychomotor development and haemoglobin concentration. The 'expected rate' of development (shown by vertical broken line) is based on the 50 centiles at 18 and 20 months (see text).

who received iron was not significantly greater than in those who did not (mean (SD) increase: $4 \cdot 0(2 \cdot 6)$ $v 3.2(2.3)$ skills) nor was it in those whose haemoglobin rose by at least $2 \mathrm{~g} / \mathrm{dl}$ compared with those whose haemoglobin did not $(4.3(2.7) \vee 3.4$ $(2 \cdot 4)$ skills).

Individual results were then inspected. Figure 4 shows the changes in haemoglobin concentration and the increase in number of items passed between assessments.

Overall, there was only a weak relation between the two (Spearman regression coefficient $0 \cdot 18$, $\mathbf{p}=0.08$ ). Two distinct effects, however, were seen. The average child staying on the 50th centile between 18 and 20 months would acquire six more skills (see Methods). This average rate of development was achieved by 15 of the treated children $(31 \%)$ but only six of the $49(12 \%)$ in the placebo group $\left(p<0.05\right.$ by $\chi^{2}$ test $)$. Alternatively, this average rate of development was achieved by 10 of the $27(37 \%)$ children whose haemoglobin concentration rose at least $2 \mathrm{~g} / \mathrm{dl}$ but only 11 out of 70 $(16 \%)$ whose concentration rose by less than $2 \mathrm{~g} / \mathrm{dl}$ $(\mathrm{p}<0.05)$.

Combining these two points then, 'effective treatment' could be defined as 'received treatment with iron and haemoglobin rose by less than $2 \mathrm{~g} / \mathrm{dl}$ '. The average rate of development was achieved by 10 of the $24(42 \%)$ effectively treated children but by only six out of $47(13 \%)$ of those who had not received effective treatment (neither received iron nor whose haemoglobin rose by more than $2 \mathrm{~g} / \mathrm{dl})(\mathrm{p}<0.02)$.
Nevertheless, it will be noted that 14 children failed to acquire six more skills even though they had received iron and their haemoglobin had risen by more than $2 \mathrm{~g} / \mathrm{dl}$.

\section{Discussion}

In this study toddlers with anaemia who received treatment with iron for two months when compared with a control group with anaemia who did not receive treatment with iron were different in two respects. They had a faster weight velocity and more of them achieved the expected increase in psychomotor skills.

Weight velocity. Weight velocity over the two month period was significantly greater in the treated group than in the control group. Increase in weight velocity during treatment with iron has been shown before both when treating toddlers with anaemia successfully ${ }^{24}$ and when giving prophylactic iron supplements to normal boys. ${ }^{25}$ This increase is seen in infants who are normal weight as well as those who are underweight at the time.

This finding may relate to the correction of the anorexia and listlessness reported as associated with iron deficiency anaemia in children ${ }^{26}$ but the effects of iron deficiency are protean. ${ }^{27}$

Psychomotor development. Our methods and results are compared with previous studies in Table 3. This study was based on a narrow, well defined age group and used a fairly long period of treatment with iron.

Before the study we were sceptical that iron deficiency had an independent effect on developmental delay. We suspected that the iron deficiency and poor development were merely effects of the same deprived environment, many aspects of which could contribute both to iron deficiency anaemia and to delayed development. Similar views had been expressed by Werkman et al. ${ }^{26}$ This, however, does not seem to be so. This intervention study suggests that there is indeed a direct relation between iron deficiency and delayed psychomotor development.

The differences between the treated and untreated groups and the below or above $2 \mathrm{~g} / \mathrm{dl}$ rise in haemoglobin groups were clearest when the 'expected' achievement of six extra skills was in effect counted as 'success' or 'failure' of intervention. We suspect this indicates a 'threshold' effect; once treatment with iron has an effect the acquisition of extra skill proceeds rapidly.

A large number (5-30\%) of young children have been found to be anaemic in various surveys, ${ }^{2} 329-32$ and many more may be iron deficient (21$55 \%) .^{29-32}$ Two studies have indicated that iron 


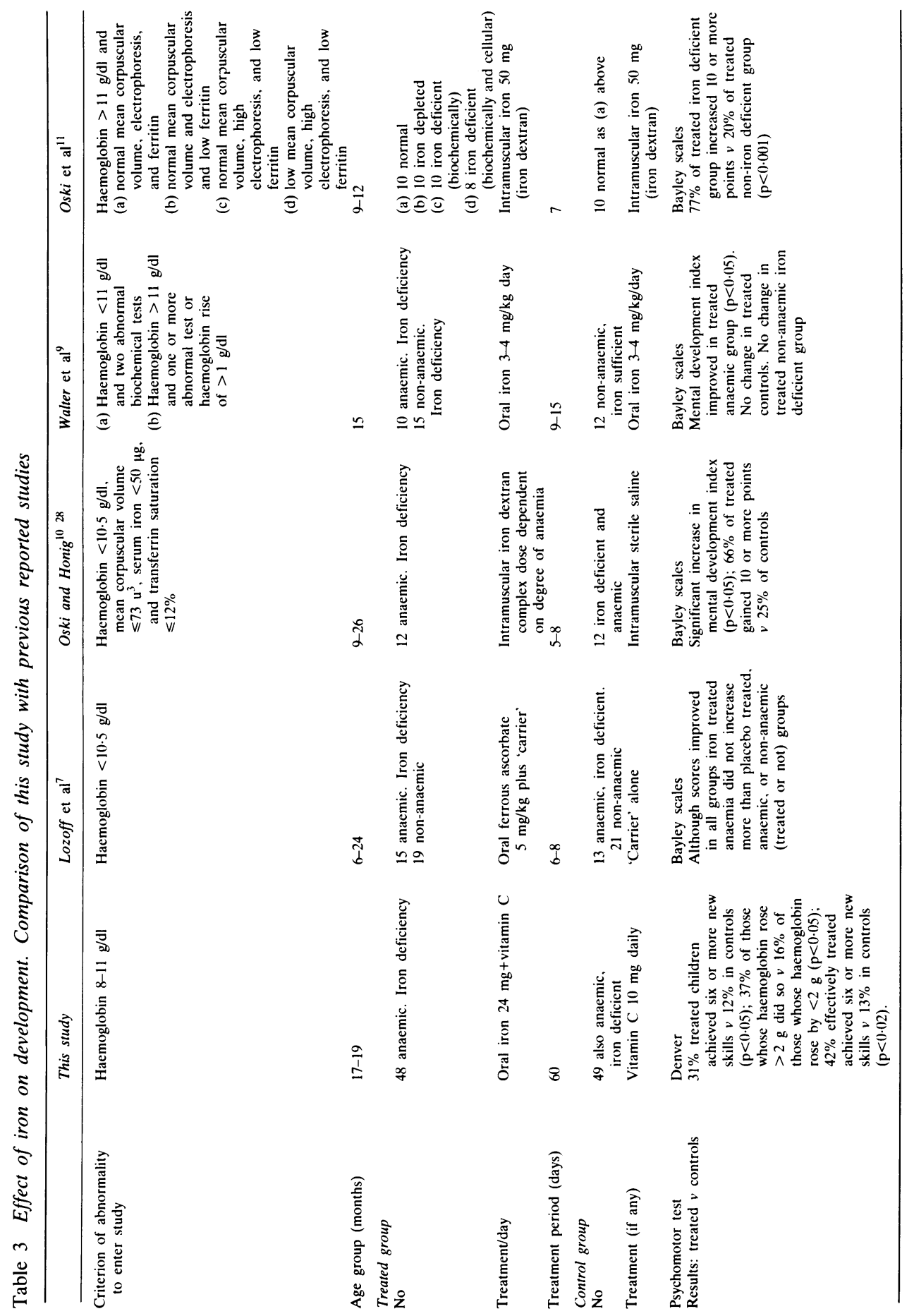


deficiency may affect development even before the children become anaemic (haemoglobin $<11 \mathrm{~g} / \mathrm{dl}$ ). ${ }^{9}{ }^{11}$ Long term iron deficiency may, therefore, have major effects on learning and scholastic performance, and studies in school age children seem to support this. ${ }^{53}$ There is, therefore, mounting evidence and concern ${ }^{29}$ that iron deficiency anaemia can produce delayed development in children, and there has been some suggestion that this is not readily reversible. ${ }^{34}$ Nevertheless, in our study there was overall only a weak relation between rise in haemoglobin concentration and improved development. Furthermore, a number of children failed to show a satisfactory improvement in development despite a definite rise in their haemoglobin concentration. So it is very unlikely that iron deficiency is the only culprit in the slower development of underprivileged children.

Implications for the child health services. While iron deficiency anaemia is not the only factor in the slower development of children living in underprivileged circumstances, it is one that at least can be easily identified and treated. The implications for the child health services are important. In our opinion a programme is needed to hunt out and treat iron deficiency in toddlers. The current child health services do not achieve this, although the incorporation of a haemoglobin screening test into the child health surveillance programme would not be difficult. The logistics of providing a few pennyworth of iron against those of repairing social disadvantage do not bear comparison.

Haemotological investigations were performed in the Haematology Department, Selly Oak Hospital (Dr E Ball and Dr J Murray). Carol Benson, Helen Macaulay, and Julie Reeves were the project nurses and Rahat Karim acted as interpreter. Figures were produced by the Medical Illustration Department, Birmingham Children's Hospital. We thank all of them and Mrs P Cox for secretarial help and also wish to acknowledge the help and cooperation of the staff at the Balsall Heath, Greet, Small Heath, and Farm Road Child Health Clinics.

\section{References}

' Lloyd-Still JD, ed. Clinical studies on the effects of malnutrition during infancy on subsequent physical and intellectual development. Lancaster: MTP, 1976;103-59.

2 World Health Organisation. Control of nutritional anaemia with special reference to iron deficiency. WHO Tech Rep Ser 1975; No 580 .

3 Pollitt E, Leibel RL. Iron deficiency and behavior. $J$ Pediatr 1976;78:372-81.

${ }^{4}$ Elwood PC, Hughes D. Clinical trial of iron therapy on psychomotor function in anaemic women. $\mathrm{Br}$ Med $J$ 1970;iii: 254-5.

5 Webb TE, Oski FA. Iron deficiency anemia and scholastic achievement in young adolescents. $J$ Pediatr 1973;82:827-30.

6 Sulzer JL, Hansche WJ, Loenig F. Nutrition and behavior in head start children: results from the Tulane study. In: Kallen DJ, ed. Nutrition, development and social behavior. Washington DC: DHEW Publication No (NIH) 1973;73-106.

${ }^{7}$ Lozoff B, Brittenham GM, Viteri FE, Wold AW, Urrutia JJ. The effects of short term iron therapy on developmental deficits in iron deficient anemic infants. $J$ Pediatr 1982;100:351-7.

${ }^{8}$ Ǵrindulis H, Scott PH, Belton N, Wharton BA. Combiried deficiency of iron and vitamin D in Asian toddlers. Arch Dis Child 1986;61:843-8.

9 Walter T, Kovalskys J, Stekel A. Effect of mild iron deficiency on infant mental development scores. J Pediatr 1983;102: 519-22.

10 Oski FA, Honig AS. The effects of therapy on the developmental scores of iron-deficient infants. $J$ Pediatr 1978;92:21-5.

11 Oski FA, Honig AS, Hely B, Howanitz P. Effects of iron therapy on behavior performance in non-anemic, iron deficient infants. Pediatrics 1983;71:877-80.

12 World Health Organisation. Nutritional anaemias. WHO Tech Rep Ser 1972; No 503.

13 Williams HL, Johnson DJ, Haut HJ. Simultaneous spectrophotometry of $\mathrm{Fe}^{2+}$ and $\mathrm{Cu}^{2+}$ in serum denatured with guanidine hydrochloride. Clin Chem 1977;23:237-40.

14 Frankenburg WK, Dodds JB. The Denver developmental screening test. $J$ Pediatr 1967;71:181-91.

${ }^{15}$ Frankenburg WK, Dodds JB, Fandal AW. Denver developmental screening test: manual workbook for nursing and paramedical personnel. Colorado: University of Colorado Medical Centre, 1973.

${ }^{16}$ Miller V, Onotera RT, Deinard AS. Denver developmental screening test: cultural variations in south east Asian children. J Pediatr 1984;104:481-2.

17 Bryant GM, Davies KJ, Newcombe RG. Standardisation of the Denver developmental screening test for Cardiff children. Dev Med Child Neurol 1979;21:353-64.

18 National Centre for Health Statistics. NCHS Growth charts. Vital Health Stat [11] 1976.

19 Gore S. Assessing clinical trials-trial discipline. Br Med J $1981 ; 283: 211-3$.

20 Dallman PR, Siimes MA. Percentile curves for hemaglobin and red cell volume in infancy and childhood. $J$ Pediatr 1979;94: 26-31.

${ }^{21}$ Nathan DG, Oski FA. Hematology of infancy and childhood. 2nd ed. Philadelphia: WB Saunders, 1981;1555.

22 Siimes MA, Addiego JE, Dallman PR. Ferritin in serum: diagnosis of iron deficiency and iron overload in infants and children. Blood 1974;4:581-90.

${ }^{23}$ Tanner JM, Whitehouse R, Takaishi M. Standards from birth to maturity for height, weight, height velocity and weight velocity. British children 1965. Parts I and II. Arch Dis Child 1966; 41:454-71,613-35.

24 Judisch JM, Naiman JL, Oski FA. Fallacy of the fat iron deficient child. Pediatrics 1966;37:987-90.

25 Burman D. Haemoglobin levels in normal infants aged 3-24 months and the effect of iron. Arch Dis Child 1972;47:261-71.

${ }^{26}$ Werkman SL, Shifman L, Skelly T. Psychosocial correlates of iron deficiency anaemia in early childhood. Psychosom Med 1964;26:125-34.

27 Oski FA. The non-hematologic manifestations of iron deficiency. Am J Dis Child 1979;133:315-22.

${ }^{28}$ Honig AS, Oski FA. Developmental scores of iron deficient infants and the effects of therapy. Infant Behaviour and Development. 1978;1:168-76.

29 Oski FA. Iron deficiency-facts and fallacies. Pediatr Clin North Am 1985;32:493-7.

30 Goel KM, Logan RW, House F, et al. The prevalence of haemoglobinopathies, nutritional iron and folate deficiencies in native and immigrant children in Glasgow. Great Britain Health Bulletin 1978;36:176-82. 
${ }^{31}$ Haddy TB, Jurkowski C, Brody H, Kallen DJ, CzajkaNarins DM. Iron deficiency with and without anemia in infants and children. Am J Dis Child 1974;128:787-93.

32 Ehrhardt P. Iron deficiency in young Bedford children from different ethnic groups. Br Med J 1986;292:90-3.

${ }^{33}$ Pollitt E, Soemantri AG, Yunis F, Scrimshaw NS. Cognitive effects of iron deficiency anaemia. Lancet 1985;i:158.
${ }^{34}$ Cantwell RJ. The long term neurological sequelae of anemia in infancy. Pediatr Res 1974;8:342.

Correspondence to Dr B A Wharton, Maternal and Child Health Unit, Sorrento Maternity Hospital, Wake Green Road, Moseley, Birmingham B13 9HE, England.

Received 26 May 1986

Twenty five years ago

The reproductive histories of mothers of patients suffering from congenital diplegia

\section{T T S Ingram and Elspeth M Russell (Edinburgh)-Arch Dis Child 1961;36:34-41}

'Two hundred mothers with children suffering from congenital diplegia were studied, 117 boys and 83 girls, and 20 were one of twins. Thier ages ranged from 13 months to 30 years, and they tended to be preselected by social class, intelligence and probably other characteristics, with an excess of patients in social classes I and II.'

This and a previous series were assessed. 'The reproductive histories of the mothers of diplegic patients in the two series were examined. The mothers were older when they married and more were over 30 years of age when they gave birth to diplegic children than expected. They had fewer conceptions than married child-bearing women in the population of Scotland and their pregnancies were more widely spread. A high proportion of their pregnancies aborted or were otherwise abnormal. Many of their offspring were stillborn, died in infancy or showed neurological or other defects if they survived. Less than half the conceptions resulted in the birth of healthy offspring who survived the first year of life. There tended to be periods of relatively decreased fertility immediately before and after the birth of patients. Pregnancies contiguous to those resulting in the birth of diplegic children were more often abnormal than those which were more remote.

'The findings support the thesis that mothers of diplegic patients may have underlying abnormalities of reproductive capacity which may be responsible for both disorders of pregnancy, labour and delivery, and for the production of abnormal offspring. The causes are obscure but maternal age may be a factor, as may chronic illness (diabetes, thyrotoxicosis and gynaecological disorders) affecting one-fifth of these mothers. Male reproductive function and mutating or recessive genes also have to be considered.'

(Dr Tom Ingram was one of the first paediatricians to devote a large part of his time and energies to research in the field of cerebral palsy. Apart from helping to develop an excellent service for children with cerebral palsy in Edinburgh he contributed much to the epidemiology, aetiology, and treatment of these children. NEIL GORDON.) 